\title{
Article
}

\section{TIMP1 and TIMP2 Downregulate TGF $\beta$ Induced Decidual-like Phenotype in Natural Killer Cells}

\author{
Adriana Albini ${ }^{1, *, \dagger}{ }^{3}$, Matteo Gallazzi ${ }^{2, \dagger}{ }^{+}$, Maria Teresa Palano ${ }^{3}{ }^{-}$, Valentina Carlini ${ }^{4}$, Riccardo Ricotta ${ }^{5}$, \\ Antonino Bruno $^{3, *(\mathbb{D}}$, William G. Stetler-Stevenson ${ }^{6, \mp(1)}$ and Douglas M. Noonan ${ }^{2,4, \mp(1)}$
}

1 Laboratory of Vascular Biology and Angiogenesis, IRCCS MultiMedica, 20138 Milan, Italy

2 Immunology and General Pathology Laboratory, Department of Biotechnology and Life Sciences, University of Insubria, 21100 Varese, Italy; m.gallazzi7@uninsubria.it (M.G.); douglas.noonan@uninsubria.it (D.M.N.)

3 Laboratory of Innate Immunity, Unit of Molecular Pathology, Biochemistry and Immunology, IRCCS MultiMedica, 20138 Milan, Italy; mariateresa.palano@multimedica.it

4 Unit of Molecular Pathology, Biochemistry and Immunology, IRCCS MultiMedica, 20138 Milan, Italy; valentina.carlini@multimedica.it

5 IRCCS MultiMedica, 20099 Sesto San Giovanni, MI, Italy; riccardo.ricotta@multimedica.it

6 Extracellular Matrix Pathology Section, Laboratory of Pathology, National Cancer Institute, National Institute of Health, Bethesda, MD 20892, USA; sstevenw@mail.nih.gov

* Correspondence: adriana.albini@multimedica.it (A.A.); antonino.bruno@multimedica.it (A.B.)

+ These authors contributed equally to this work.

$\ddagger$ These are co-last authors.

Citation: Albini, A.; Gallazzi, M.; Palano, M.T.; Carlini, V.; Ricotta, R.; Bruno, A.; Stetler-Stevenson, W.G.; Noonan, D.M. TIMP1 and TIMP2 Downregulate TGF $\beta$ Induced Decidual-like Phenotype in Natural Killer Cells. Cancers 2021, 13, 4955. https: / / doi.org/10.3390/ cancers13194955

Academic Editors: Paola Vacca,

Laura Chiossone and

Emanuela Marcenaro

Received: 19 June 2021

Accepted: 27 September 2021

Published: 1 October 2021

Publisher's Note: MDPI stays neutral with regard to jurisdictional claims in published maps and institutional affiliations.

Copyright: (c) 2021 by the authors. Licensee MDPI, Basel, Switzerland. This article is an open access article distributed under the terms and conditions of the Creative Commons Attribution (CC BY) license (https:// creativecommons.org/licenses/by/ $4.0 /)$.
Simple Summary: Cancer patients are characterized by NK cells with altered surface markers, such as CD56 brightness, CD9, CD49a (pro-angiogenic) and PD-1, and TIM-3 (exhaustion), that favor immune escape. Transforming growth factor-beta (TGF $\beta$ ) is a major tumor-derived cytokine that favors cancer growth and supports pro-angiogenic activities in NK cells by inducing pro-angiogenic molecules. TIMP-1 and TIMP-2 play a crucial role in extracellular matrix (ECM) regulation, wound healing, pregnancy and cancer, and there is increasing evidence that they are immune-modulatory. We found that recombinant TIMP-1 and -2 can partially contrast the induction of pro-tumor/proangiogenic decidual-like polarization of NK cells by TGF $\beta$.

Abstract: Natural Killer (NK) cells have been found to be anergic, exhausted and pro-angiogenic in cancers. NK cell from healthy donors, exposed to TGF $\beta$, acquire the CD56 ${ }^{\text {bright }} \mathrm{CD}^{+} \mathrm{CD} 49 \mathrm{a}^{+}$deciduallike-phenotype, together with decreased levels of NKG2D activation marker, increased levels of TIM-3 exhaustion marker, similar to cancer-associated NK cells. Tissue inhibitors of metalloproteases (TIMPs) exert dual roles in cancer. The role of TIMPs in modulating immune cells is a very novel concept, and the present is the first report studying their ability to contrast TGF $\beta$ action on NK cells. Here, we investigated the effects of TIMP1 and TIMP2 recombinant proteins in hindering decidual-like markers in NK cells, generated by polarizing cytolytic NK cells with TGF $\beta$. The effects of TIMP1 or TIMP2 on NK cell surface antigens were determined by multicolor flow cytometry. We found that TIMP1 and TIMP2 were effective in interfering with TGF $\beta$ induced NK cell polarization towards a decidual-like-phenotype. TIMP1 and TIMP2 counteracted the effect of TGF $\beta$ in increasing the percentage of $\mathrm{CD}_{5} 6^{\text {bright, }} \mathrm{CD} 16^{-}, \mathrm{CD}^{+}$and $\mathrm{CD} 49 \mathrm{a}^{+}$, and restoring normal levels for TIMP 1 and 2 also inhibited decrease levels of the activation marker NKG2D induced by TGF $\beta$ and decreased the TGF $\beta$ upregulated exhaustion marker TIM-3. NK cell degranulation capabilities against K562 cells were also decreased by TGF $\beta$ and not by TIMP1 or TIMP2. TIMP1 treatment could partially restore degranulation marker CD107a expression. Treatment with recombinant TIMP-1 or TIMP-2 showed a trend, although not statistically significant, to decrease CD49a ${ }^{+}$and TIM-3+ expression and increase NKG2D in peripheral blood NK cells exposed to conditioned media from colon cancer cell lines. Our results suggest a potential role of TIMPs in controlling the tumor-associated cytokine TGF $\beta$-induced NK cell polarization. Given the heterogeneity of released factors within the TME, it is clear that TGF $\beta$ stimulation represents a model to prove TIMP's new properties, but it cannot be envisaged as a soloist NK cell polarizing agent. Therefore, further studies from the scientific community will 
help defining TIMPs immunomodulatory activities of NK cells in cancer, and their possible future diagnostic-therapeutic roles.

Keywords: TIMP-1; TIMP-2; TGF $\beta$; Natural Killer cells; decidual-NK cells; tumor microenvironment; cancer; innate immunity; inflammation; angiogenesis

\section{Introduction}

Tissue inhibitors of metalloproteases (TIMPs) were discovered in the 1980s [1], mostly for their function, as the name says, in inhibiting the enzymatic activity of metalloproteases (MMPs). There are four known members, TIMPs 1-4, with both similarities and many differences in functions, depending also on the microenvironment stimuli [2]. TIMPs are proteins of 184-194 amino acids and $\sim 21 \mathrm{kDa}$ in molecular weight, showing $\sim 40 \%$ identity ( $60 \%$ similarity) in sequence. TIMP2 and TIMP4 are structurally related, sharing most similarities with one another, while TIMP1 represents the most unique member of the TIMP protein family. We were the first to discover the role of TIMP2 in inhibiting tumor invasion [3].

TIMPs have been found to exert biological activities independent of MMP inhibition; TIMP perturbations lead to complex and unexpected context- and tissue-specific biological outcomes [2]. Roles of TIMPs, besides inhibition of invasion and metastases, have been identified in anti-angiogenesis, modulation of stem cell properties, neuronal regulation, and monocyte functions [2,4].

In contrast to being a MMP inhibitor and therefore an anti-invasive agent, clinical studies have shown a paradoxical association of high TIMP1 expression with a poor prognosis and more advanced stage tumors in a variety of cancer patients (i.e., lung, brain, prostate, breast, colon, and endometrial) [2,5,6]. Lack of TIMP1 (but not TIMP2) immunostaining is associated with a favorable prognosis in patients with node-positive high-grade breast carcinoma [2,7]. TIMP2 is an anti-angiogenic protein [4,8], and tumorbearing timp2-/ - mice show significantly increased inflammatory cells, myeloid-derived suppressor cell (MDSC; CD11 b and Gr- $1^{+}$) and endothelial cells (ECs) in tumors compared to the wild type [9]. TIMP2, but not TIMP1, secreted by monocyte-like cells, is a potent suppressor of invadopodium formation in breast [10] and pancreatic [11] cancers. This shows that TIMPs can behave as stress-response genes similar to "alarmins" [12]. Alarmins are danger-signal molecules produced by the cell under stress (i.e., hypoxia, nutrient starvation, inflammation), and they are endogenous, immune-activating proteins/peptides released as a result of degranulation or in response to immune induction [12]. Non-MMPinhibitory and oncogenic functions of TIMP1 are mediated by the initiation of intracellular signaling via its tetraspanin cell surface receptor CD63 [13].

The TGF $\beta$ signaling pathway governs key cellular processes under physiologic conditions and is deregulated in many pathologies, including cancer [14-16]. TGF $\beta$ is a multifunctional cytokine that acts in a cell- and context-dependent manner as a tumor promoter or tumor suppressor [14-16]. TGF $\beta$-induces TIMP1 from hepatic stellate cells, subsequently bound to CD63, leading to FAK activation in hepatocellular carcinoma cells, suggesting that TIMP1 can function as a mediator of TGF $\beta$-regulated crosstalk between stromal and cancer compartments [2,17].

On the other hand, TIMP2 functions almost exclusively in an anti-tumorigenic manner. It has been shown that TIMP2 inhibits in vivo VEGF-induced angiogenic responses and primary tumor growth of human lung xenografts, as well as inhibiting metastasis in an orthotopic, murine triple-negative breast cancer (TNBC) model [18-20].

ILCs (innate lymphoid cells) represent a recently identified heterogeneous family of mononuclear hematopoietic cells found mostly in solid tissues [21,22]. Based on their lymphoid morphology, surface antigens, transcription factor expression and cytokine production (Th1, Th2 and Th17-like), ILCs have been classified into three major groups, 
termed ILC1, ILC2 and ILC3 [22,23]. Whether ILCs can be defined as friends or foes in cancer insurgence and progression is still a matter of debate [21,22,24].

NK cells are innate lymphoid cells involved in tumor immunosurveillance by inducing cancer cell lysis both directly (via perforin/granzyme system) or indirectly (via secretion of TNF $\alpha$ and IFN $\gamma$ ) [21,25]. NK cells develop altered phenotypes in many cancer types, which includes acquisition of anergy and cell exhaustion (increased levels of PD-1 and TIM-3) [26-28]. Apart from anergy, we found that tumor-associated peripheral blood NK cells (TANKs) in non-small cell lung cancer (NSCLC), pleural effusions and colorectal cancers (CRC) and prostate cancer patients acquire pro-angiogenic phenotype and functions [29-33]. We observed that tumor-associated (TANKs) and tumor-infiltrating (TINKs) NK cells in cancer patients can acquire phenotype and functions similar to NK cells in the developing decidua [34-37]. The decidual NK (dNK) cells are characterized by a CD56 $6^{\text {superbright }} \mathrm{CD} 16^{\text {neg }}$ phenotype and by the presence of CD9 (a member of the tetraspanin protein family that plays a role in cell adhesion and cell motility) and CD49a (an integrin alpha 1 subunit that binds collagen and laminin) [35,38]. These dNK cells are poorly cytotoxic and are necessary to remodel spiral arteries during pregnancy $[34,35,39,40]$. Within the decidua, Natural Killer (NK) cells play a critical role in the tolerance of the developing fetus, the modulation of angiogenesis and decidualization, all necessary processes associated with pregnancy. dNKs produce angiogenic factors: VEGF, PIGF and IL-8 (CXCL8) [35,39-41], angiogenin [40,41] and angiopoietin 1 and $2[35,41]$. They also support tissue remodeling through the expression of matrix metalloproteinases (MMP-9). MMPs and TIMPs expression was observed in both decidual tissues and in dNK cells [42]. It was found that a wide variety of MMPs are expressed at the human fetal-maternal interface, supporting the highly invasive cellular activity and ECM remodeling that occurs during placental development. Interestingly, some NKG2D ligands (MICA, MICB, ULBP-2 and ULBP-3) are secreted from NSCLC [43], osteosarcomas [44] and gastric [45] cancer cells and may be shed by MMP-mediated cleavage. For example, upregulation of MMP activity can induce a downregulation of the expression of NKG2D ligands in gastric cancer cells, leading to lower-level cancer susceptibility to NK cells [45]. Therefore, TIMPs could be relevant in NK cell recognition activities. Supernatants derived from decidual NK cells show pro-angiogenic action in vitro and in vivo and can significantly increase tumor growth and angiogenesis [39]. We have found that CRC TANKs expressed CD9 and CD49a, as well as increased VEGF and CXCL8, production and release when compared with healthy controls NK cells, behaving similarly to dNK [30]. We have also described a paradoxical increased expression of TIMP1 and TIMP2 in CRC NK. All these features support the rationale that pro-angiogenic tumor-associated NK cells, as "onco-fetal" NK, resume features of embryo "nurturing" cells [37].

Transforming growth factor- $\beta$ (TGF $\beta$ ) is associated with dNK cell polarization $[46,47]$ and is present in the tumor microenvironment (TME). A combination of TGF $\beta$, hypoxia and a demethylating agent induces a dNK-like phenotype in healthy donor NK cells [48]. TGF $\beta$ converts NK cells into the intermediate ILC- 1 cell population, which is unable to control local tumor growth and metastasis [49]. We demonstrated that TGF $\beta$ can also generate decidual-like NK cells, able to produce VEGF and PlGF [32].

Here, we show the ability of TIMP1 and TIMP2 to contrast the TGF $\beta$-induced deciduallike polarization of cytolytic NK cells. In particular, TIMP1 and TIMP2 counteracted the effect of TGF $\beta$ in increasing the percentage of CD $56^{\text {bright }}, \mathrm{CD} 16^{-}, \mathrm{CD}^{+}$and CD49a ${ }^{+}$, restoring normal levels. TIMPs 1 and 2 also inhibited decreased levels of the lytic marker NKG2D induced by TGF $\beta$ and hindered the TGF $\beta$ upregulated TIM-3.

NK cell degranulation abilities on K562 cells were also decreased by TGF $\beta$ but not by TIMP1 or TIMP2. However, only TIMP1 could also partially restore degranulation marker CD107a, while TIMP2 showed a small but not significant trend.

In preliminary experiments, we treated NK cells with conditioned media (CM) of colon cancer cell lines. CD9, CD49a and TIM3 expression was increased by CM, as previously reported, while TIMP1 and 2 showed a trend in counteracting the TGF $\beta$ effects. Compared 
to TGF $\beta$, the cytokine IL-6 was not able to induce a decidual-like polarization in cytolytic NK cells.

Our results suggest a potential role of TIMPs in controlling the angiogenic switch in tumor-associated NK cells induced by TGF $\beta$ and provide the rational for the possible use of TIMPs in the re-education of anergic/pro-angiogenic NK cells in cancer patients.

\section{Materials and Methods}

\subsection{Preparation of the Recombinant TIMP-1 and TIMP-2}

Recombinant TIMP1 and TIMP2 with 6X His-epitope tag were expressed, purified and tested negative for Endotoxin in the MTBM assay (Animal Health Diagnostic Laboratory, NCI-Frederick, Frederick, MD, USA). TIMP1 and TIMP2 preparations showed $>98$ purity. Protein concentration was determined by A280, bicinchoninic acid (BCA) assay and sandwich ELISA assays. Lyophilized TIMP1 and TIMP2 powder was reconstituted in Hanks Balanced Salt Solution (HBSS), sterile-filtered $(0.22 \mu \mathrm{m})$ and stored at $-80^{\circ} \mathrm{C}$ until use [50]. Preliminary experiments were performed to choose the best concentration of the recombinant TIMPs for NK cell treatment.

\subsection{Isolation of Mononuclear Cells from Whole Blood of Healthy Donors}

Twelve milliliters of heparinized whole blood, collected from healthy donors, was diluted with PBS 1:1 $(v / v)$, then subjected to a density gradient stratification with Ficoll Histopaque-1077 (Sigma Aldrich, St. Louis, MO, USA) at 500 $\times g$ for $20 \mathrm{~min}$. The white ring interface, composed of total mononuclear cells (MNCs), was collected, washed twice in PBS, then used for subsequent experiments for NK cell polarization and treatments. Human samples were collected from healthy donors, enrolled within studies approved by the institutional review board ethics committees (protocol no. 0024138 04/07/2011, University of Insubria, Italy and protocol no. 102 10/2011, IRCCS MultiMedica, Milan, Italy) and according to the Helsinki Declaration of 1975 as revised in 2013. All subjects included in the study signed the informed consent, in accordance with the Helsinki Declaration of 1975 as revised in 2013.

\subsection{NK Cell Polarization and Treatments with TIMPs}

A total of $3 \times 10^{6}$ mononuclear cells (MNCs), from peripheral blood of healthy donors, were polarized with TGF $\beta(10 \mathrm{ng} / \mathrm{mL})$ alone or in combination with TIMP-1 $(0.1 \mu \mathrm{g} / \mathrm{mL})$ or TIMP-2 $(0.1 \mu \mathrm{g} / \mathrm{mL})$ or IL-6 $(25 \mathrm{ng} / \mathrm{mL})$ alone. MNCs received treatments at day zero and at $48 \mathrm{~h}$. FACS analysis was performed following $72 \mathrm{~h}$ of treatments.

\subsection{Colon Cancer Cell Line Culture and Maintenance}

The colon cancer (CC) HT-29 and the colorectal cancer (CRC) CaCo2 cell lines (ATCC) were maintained in RPMI 1640 medium, supplemented with 10\% Fetal Bovine Serum (FBS), (Euroclone, Pero, MI, Italy), $2 \mathrm{mM}$ l-glutamine (Euroclone), $100 \mathrm{U} / \mathrm{mL}$ penicillin and $100 \mu \mathrm{g} / \mathrm{mL}$ streptomycin (Euroclone). Conditioned media for NK cell polarization experiments were collected from HT-29 cells. Once cells were $80 \%$ confluent, cells were washed for $30 \mathrm{~min}$ in serum-free RPMI medium to eliminate serum residuals. Following cell layer wash, cells were maintained in serum-free RPMI medium for $48 \mathrm{~h}$ and conditioned media (CMs) were collected. CMs were concentrated using the $3 \mathrm{KDa}$ cut-off concentrations (Millipore, Burlington, MA, USA) and quantified by Bradford reagent. Aliquots of $50 \mu \mathrm{g}$ total protein were prepared and used for NK cell polarization.

\subsection{Phenotype Characterization of TGF $\beta$ or CC/CRC CM Exposed NK Treated with TIMPS}

The effects of TIMP1 and TIMP2 on decidual-like NK cells, generated by MNC stimulated by TGF $\beta$, were determined by multicolor flow cytometry, using a BD FACS Fortessa $\times 20$ analyzer, equipped with 5 lasers. A total of $2 \times 10^{5}$ of total MNCs were stained for $30 \mathrm{~min}$ at $4{ }^{\circ} \mathrm{C}$ with anti-human monoclonal antibodies (mAbs) as follows: PerCP-conjugated anti-CD3 (BW264/56), APC-conjugated anti-CD56 (REA196), FITC- 
conjugated anti-CD16 (REA589), PE-conjugated anti-CD9 (REA1071), PE-conjugated antiCD49a (REA1106), PE-conjugated anti-NKG2D (REA1228), PE-conjugated anti-TIM-3 (F382E2) and PE-conjugated anti-PD-1 (PD1.3.1.3) (all purchased by Miltenyi Biotec, Bergisch Gladbach, Germany). IL-6 alone was used as control for TGF $\beta$ activity. CM $(50 \mu \mathrm{g})$ from HT-29 or $\mathrm{CaCo} 2$ cell lines were also used as stimuli in preliminary experiments.

Following Forward/Side Scatter setting, NK cells were identified as $\mathrm{CD}^{-}$and $\mathrm{CD} 56^{+}$ cells (total NK cells). CD16 and NKG2D expression was evaluated on CD3 ${ }^{-} \mathrm{CD}^{-} 6^{+}$(total NK) gated cells. Finally, CD56 brightness, the expression of the dNK markers CD9, CD49a, expression of TIM- 3 and the expression of the exhaustion markers PD-1 and TIM3 were evaluated on total $\mathrm{CD}^{-} \mathrm{CD}^{-} 6^{+} \mathrm{NK}$ cells.

\subsection{Degranulation Assay on TGF $\beta$-Polarized NK Cells Exposed to TIMPs}

A total of $3 \times 10^{6}$ mononuclear cells (MNCs), from peripheral blood of healthy donors, were polarized in RPMI medium with TGF $\beta(10 \mathrm{ng} / \mathrm{mL})$, alone or in combination with TIMP-1 $(0.1 \mu \mathrm{g} / \mathrm{mL})$ or TIMP-2 $(0.1 \mu \mathrm{g} / \mathrm{mL})$ or IL-6 $(25 \mathrm{ng} / \mathrm{mL})$ alone. MNCs received treatments at day zero and at $48 \mathrm{~h}$. After $72 \mathrm{~h}$, polarized cells were used to detect their ability to degranulate, as detected by the CD107a expression, against the K562 cell line, according to [51-53], with minor modifications. Following $72 \mathrm{~h}$ of polarization, $2 \times 10^{5}$ MNCs were co-cultured with $2 \times 10^{5} \mathrm{~K} 562$ (E:T ratio of 1:1) in the presence of anti-CD107a- FITC (BD Biosciences, San Jose, CA, USA, H4A3), Golgi Plug (Brefeldin, BD Biosciences) and Golgi Stop (Monesin, BD Biosciences). MNC alone was used as control to detect basal degranulation activities by NK cells, MNC treated with Ionomycin (500 ng/mL, Sigma Aldrich), PMA (10 ng/mL, Sigma Aldrich), Golgi Plug (Brefeldin, BD Biosciences) and Golgi Stop (Monesin, BD Biosciences), as positive control for non-specific degranulation, while K562 cell alone was used as internal control. Cells were stimulated for $6 \mathrm{~h}$. CD107a expression, as a readout of degranulation activities, was detected by flow cytometry on $\mathrm{CD}^{+} \mathrm{CD}^{+} 6^{+}$total NK cells. Cell degranulation efficiency was finally determined by subtracting the basal degranulation (NK cells alone) from the degranulation detected in the NK cells/K562 co-culture.

\subsection{Statistical Analysis}

Statistical analysis was performed using the GraphPad Prism software v9. Flow cytometry data were analyzed using the FlowJo software, v10. Results are shown as mean \pm SEM, one-way or two-way ANOVA, followed by Tukey's post hoc test. $p$-values $(p) \leq 0.05$ were considered statistically significant.

\section{Results}

\subsection{TGF $\beta$ Is a Crucial Regulator of the Induction of Decidual-like NK Cells Activity Compared to $I L-6$}

TGF $\beta$, a major cytokine present in the tumor micro (tissue-local) and macro (circulating) environments in cancer patients, has been reported to induce the generation of anergic and decidual-like NK cells. To corroborate the notion that TGF $\beta$ acts as a major tumorassociated cytokines in the generation of decidual-like/anergic NK cells, we further tested the effects of TGF $\beta$ on NK cell polarization, as compared to IL-6, another relevant cytokine present in the tumor micro- and macro-environment. We confirmed our previously published data [33] and observed no differences in CD56 bright $\mathrm{NK}$ cell increase when compared TGF $\beta$ with IL-6 (Figure S1A), while NK cells exposed to TGF $\beta$ had increased expression of CD9, compared with not treated and IL-6-exposed NK cells (Figure S1B). Additionally, TGF $\beta$ was more effective than IL-6 in increasing the frequency of CD16-NK cells and in downregulating NKG2D, this latter in a statistically significant manner (Figure S1C,D). Finally, TGF $\beta$ significantly reduced NK cell degranulation capabilities against K562 cells, as compared to IL-6 (Figure S1E). 


\subsection{TIMP-1 and TIMP-2 Counteract the Generation of TGF $\beta$-Induced Decidual-like NK Cells}

Recently, TIMP1 has also been identified as a new immune-regulators/immunecheckpoint modulator $[9,11,30]$. In the present study, we evaluate the impact of TIMP1 and TIMP2 during NK cell polarization to a pro-angiogenic phenotype by TGF $\beta$. We investigated the ability of the administration of TIMP1 and TIMP2 to limit the polarization of cytolytic NK cells towards pro-angiogenic/decidual-like NK cells. We used healthy donor-derived NK cells, co-treated for $72 \mathrm{~h}$ with TGF $\beta(10 \mathrm{ng} / \mathrm{mL})$, and found that TIMPs were effective in reducing the percentage of $\mathrm{CD} 56^{\text {bright }} \mathrm{CD} 16^{-}$decidual-like NK cells (Figure 1A,B). The gating strategy is shown in Figure S2.

Furthermore, we investigated the ability of TIMP1 and TIMP2 to modulate the expression of the CD9 and CD49a decidual markers, induced by TGF $\beta$ exposure. We observed that CD9 (Figure 2A) and CD49a (Figure 2B) surface antigen expression was elevated by TGF $\beta$ treatment, as previously reported [46,47] for healthy control-derived NK cells and was decreased following $72 \mathrm{~h}$ of co-treatment with TGF $\beta$ plus TIMP1 or plus TIMP2. As a proof of concept, we investigated whether conditioned media from CC/CRC cell lines (HT-19 and $\mathrm{CaCo}$ ) can induce a polarizing effect, as compared to TGF $\beta$. We found in preliminary experiments that CC-conditioned media were less efficient in generating decidual-like NK cells (Figure S3). In polarization experiments, TGF $\beta$ was confirmed as a better inducer for the dNK-like polarization than IL6 (Figure S3).

We observed that TIMP1 and TIMP2 have a trend of reducing the frequency of $\mathrm{CD} 49 \mathrm{a}^{+} \mathrm{NK}$ cells when co-administered with CC CM (Figure S3).

3.3. TIMP-1 and TIMP-2 Modulate the Expression of Activation and Exhaustion Markers in TGFB-Induced Decidual-like NK Cells

NK cells isolated from cancer patients have been found to acquire anergic and exhausted phenotypes. TGF $\beta$ has been reported to participate in this process. Here, we tested the ability of TIMP-1 or TIMP-2 to limit the generation NK cells endowed with anergic/exhausted phenotypes. Both TIMP1 and TIMP2 were able to counteract the effects of TGF $\beta$-induced NK polarization by enhancing NKG2D activation receptor (Figure 3A) and decreasing the exhaustion marker TIM-3 (Figure 3B) and PD-1 (Figure S4). Internal controls for NK cell degranulation capability (Figure S5).

\subsection{TIMP-1 and TIMP-2 Modulate the Degranulation Abilities in TGF $\beta$-Polarized NK Cells}

Since we observed the ability of TIMPs to restore NKG2D expression in TGF $\beta$-induced decidual-like NK cells, together with attenuation of TIM-3 and PD-1 levels, we tested the effects of TIMPs on NK cell degranulation abilities on K562 cells. TIMP 1 and TIMP2 alone did not impair degranulation marker CD107a. We found that TIMP-1 had a positive significant capability in counteracting TGF $\beta$. (Figure 4). TIMP-2, however, only showed a trend, albeit not significant, in reverting the degranulation capabilities, when combined with TGF $\beta$ (Figure 4). 
A

CD56 bright
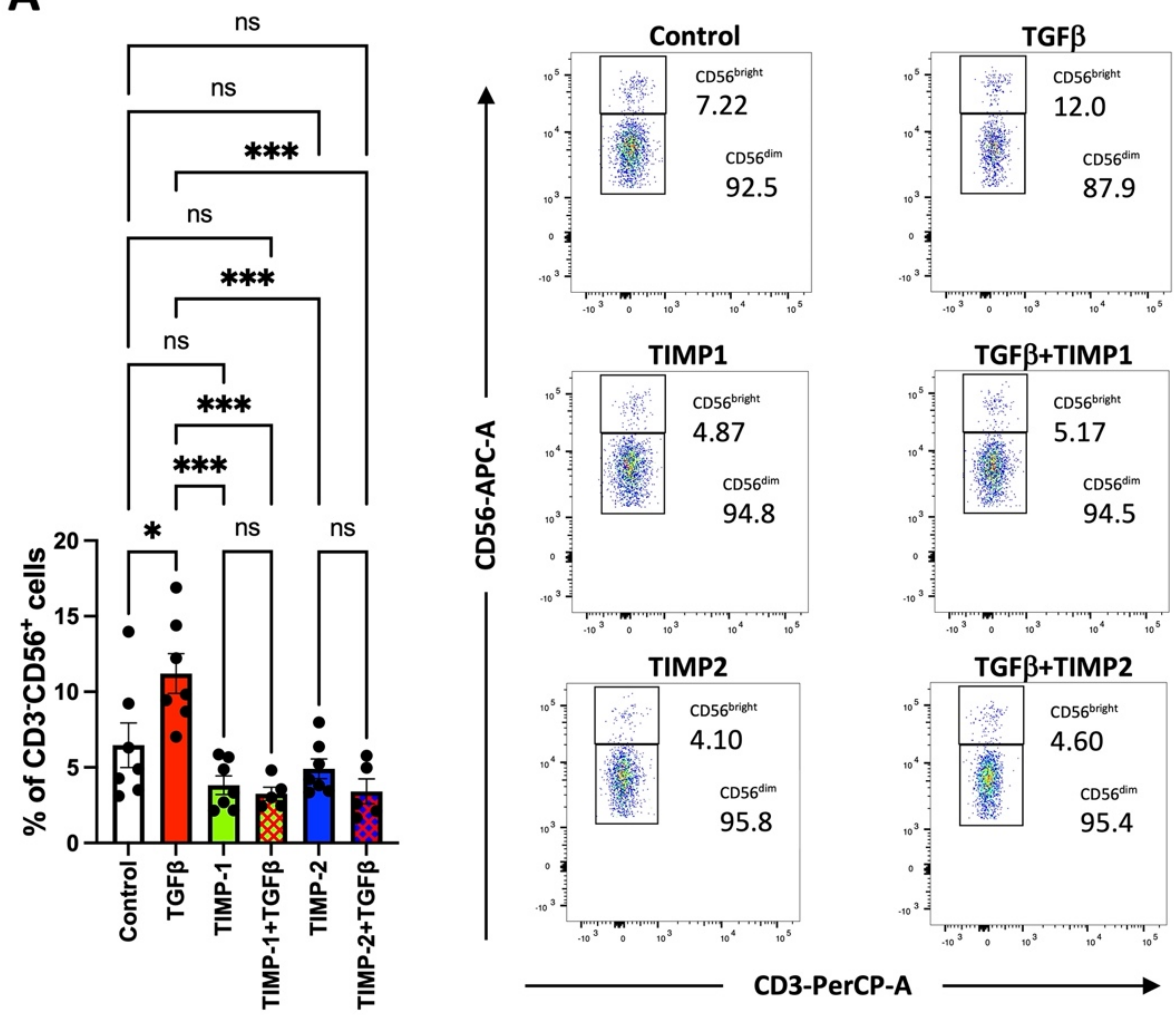

B
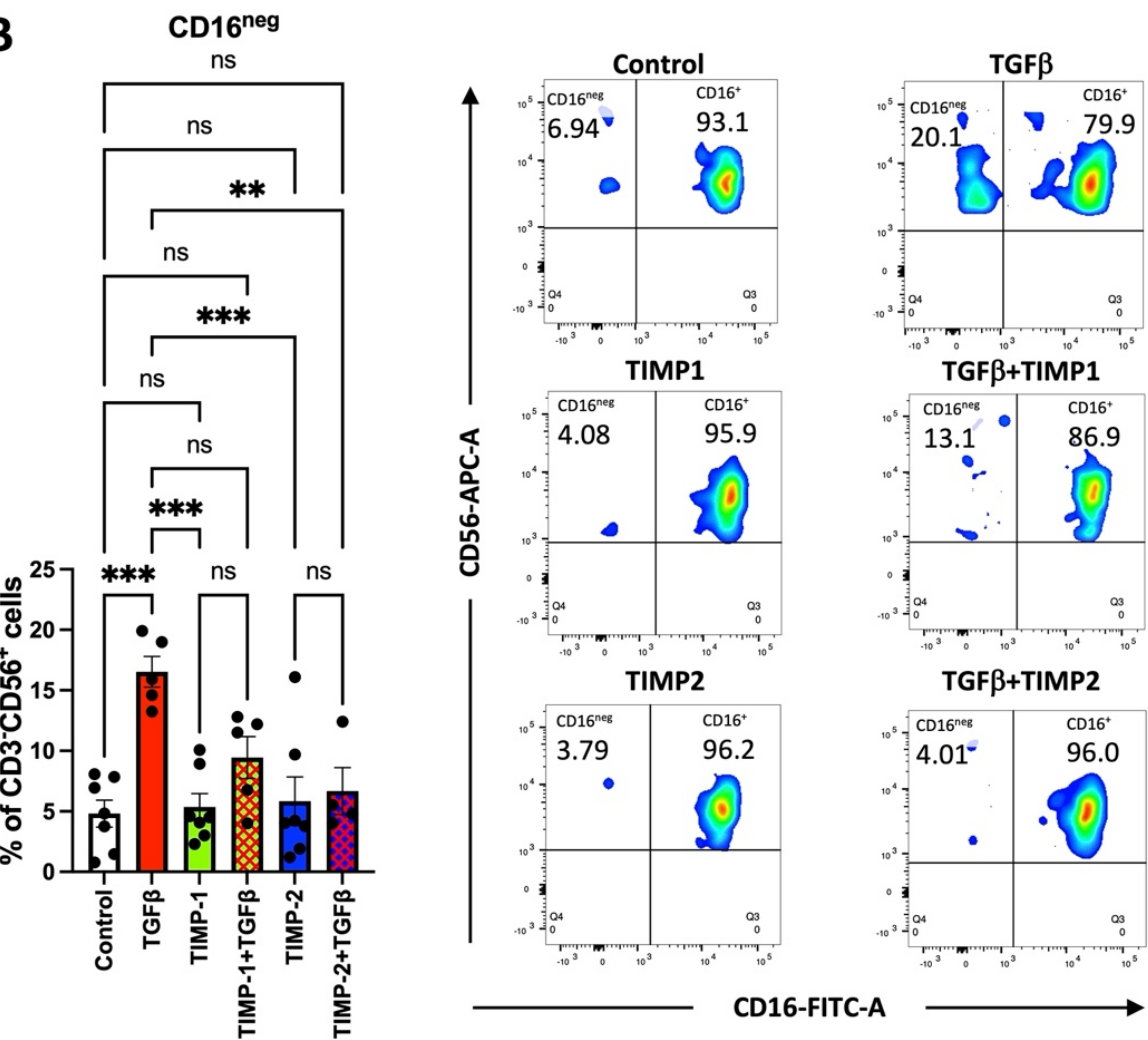

TGF $\beta+$ TIMP1

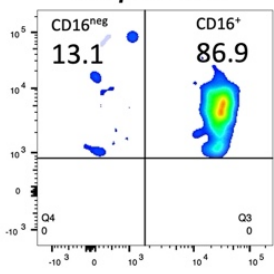

TGF $\beta+$ TIMP2

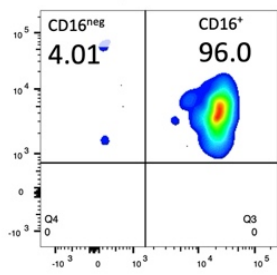

Figure 1. Healthy donor-derived NK cells exposed to TGF $\beta$ upregulate CD56 ${ }^{\text {Bright }}$ (panel A) and CD16 ${ }^{\text {neg }}$ (panel B), and TIMP1 and TIMP2 were effective in interfering with TGF $\beta$. Results are shown as \pm SEM, ANOVA, ns = not signficant; ${ }^{*} p<0.05 ;{ }^{* *} p<0.01$; ${ }^{* * *} p<0.005$. Representative plots are shown. Controls were cells in RPMI medium alone. 
A

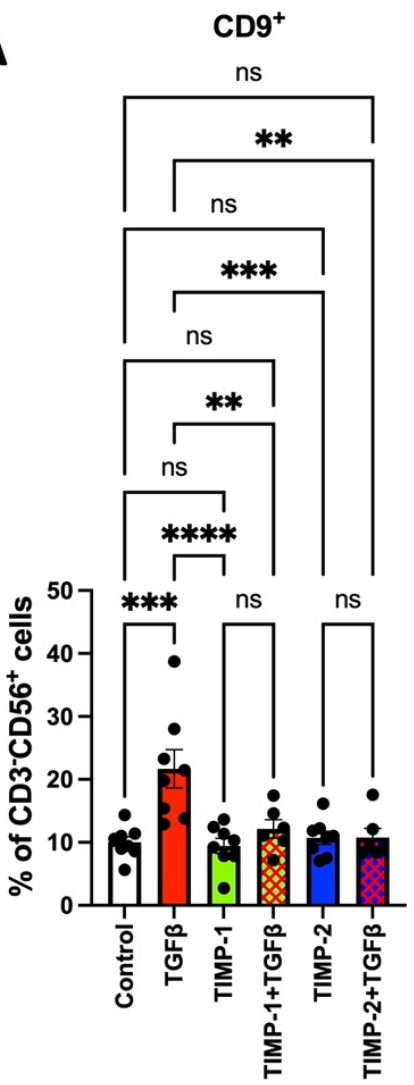

B

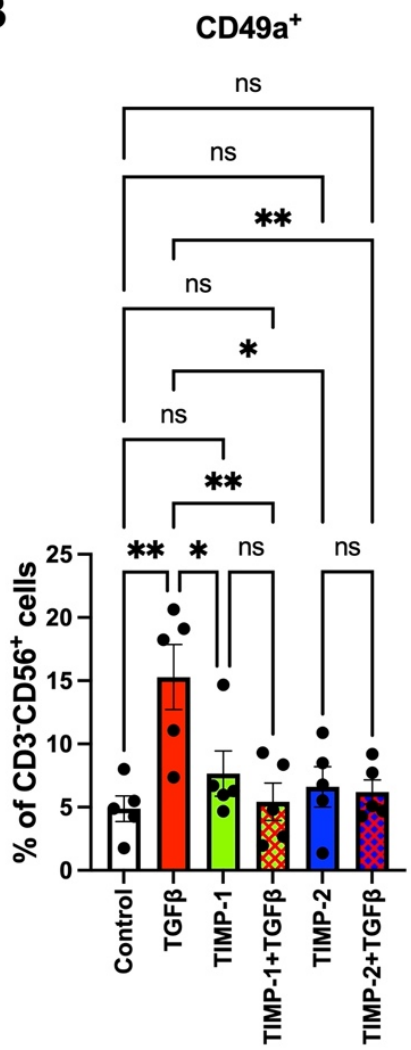

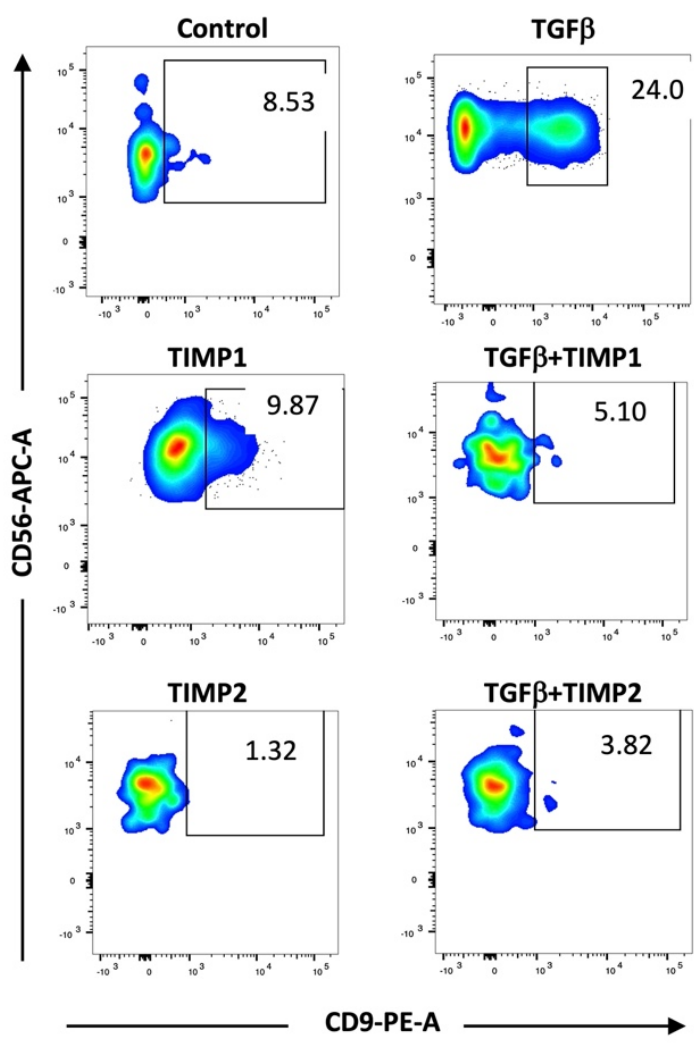

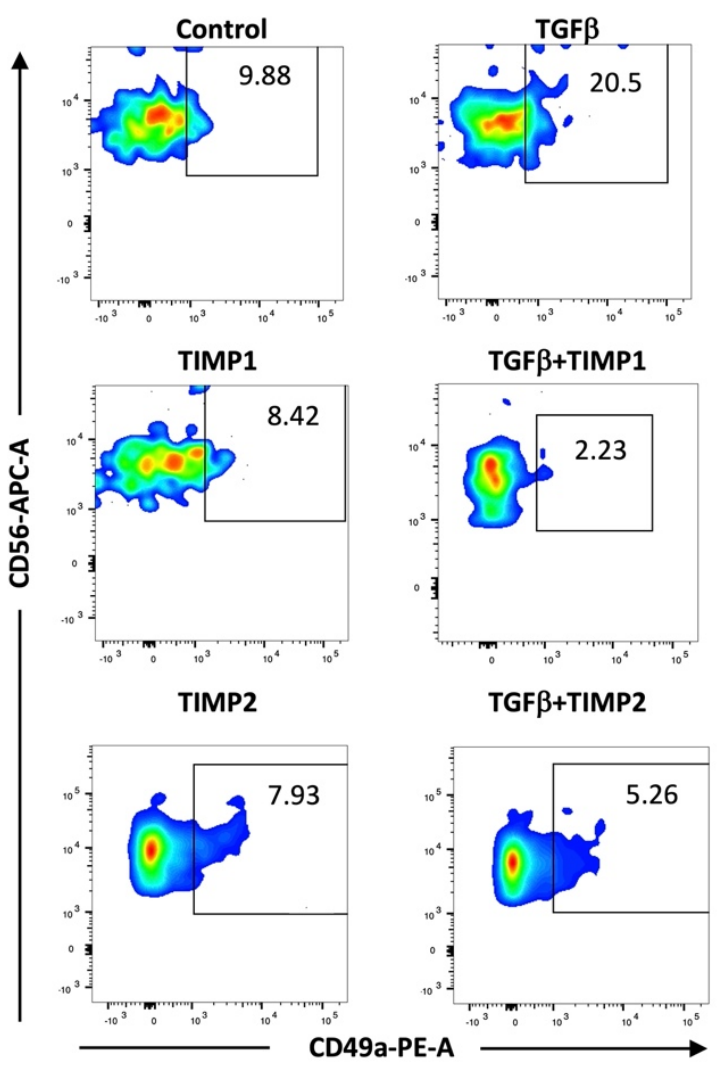

Figure 2. TGF $\beta$ in the polarization of healthy donor-derived NK TIMP1 and TIMP2 cells lowers the CD9 (panel A) and CD49a (panel B) levels (dNK markers) induced by TGF $\beta$. Results are shown as mean \pm SEM, ANOVA, $\mathrm{ns}=$ not signficant; ${ }^{*} p<0.05 ;{ }^{* *} p<0.01 ;{ }^{* * *} p<0.005 ;{ }^{* * *} p<0.001$. Representative plots are shown. Controls were cells in RPMI medium alone. 

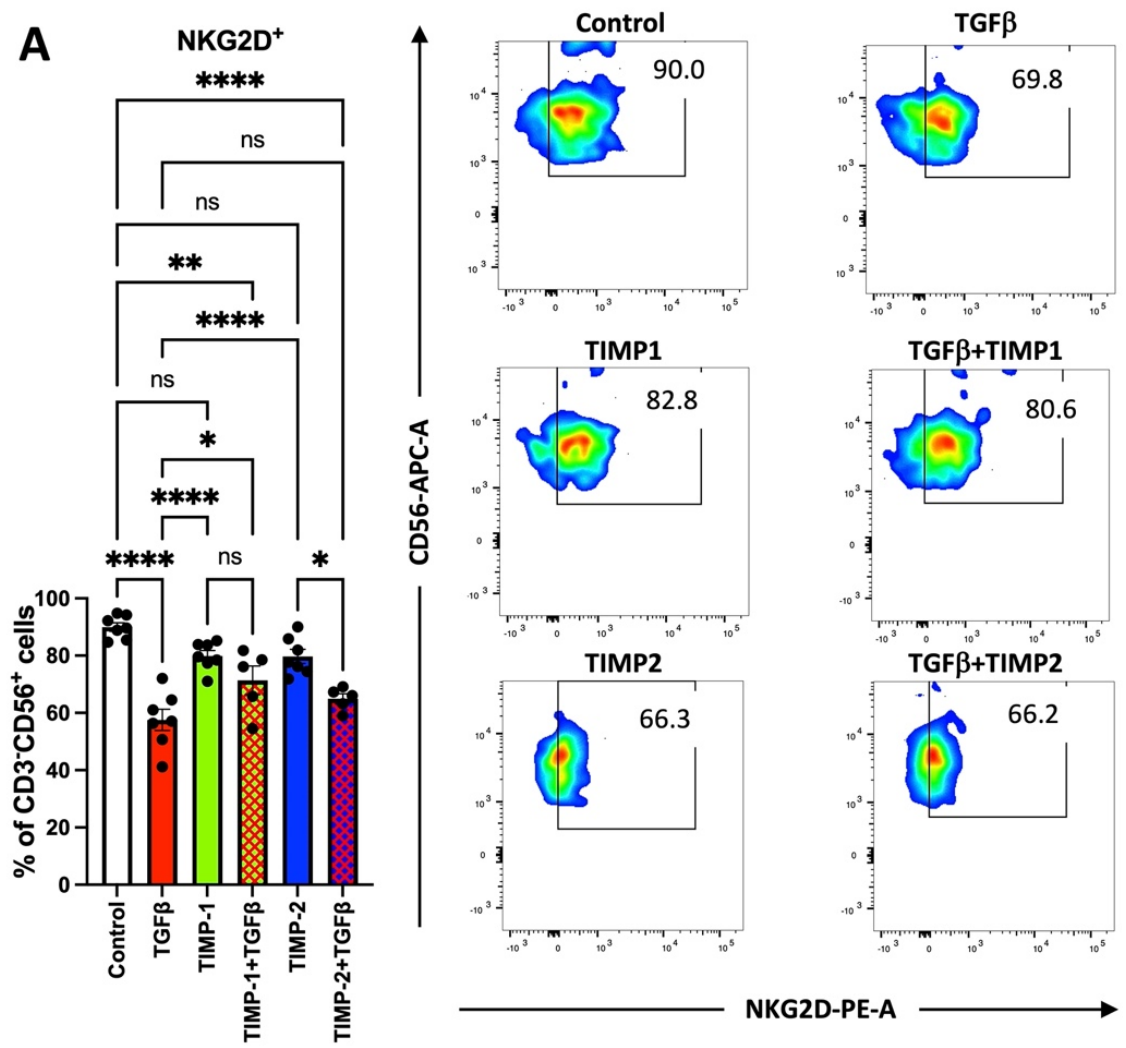

B
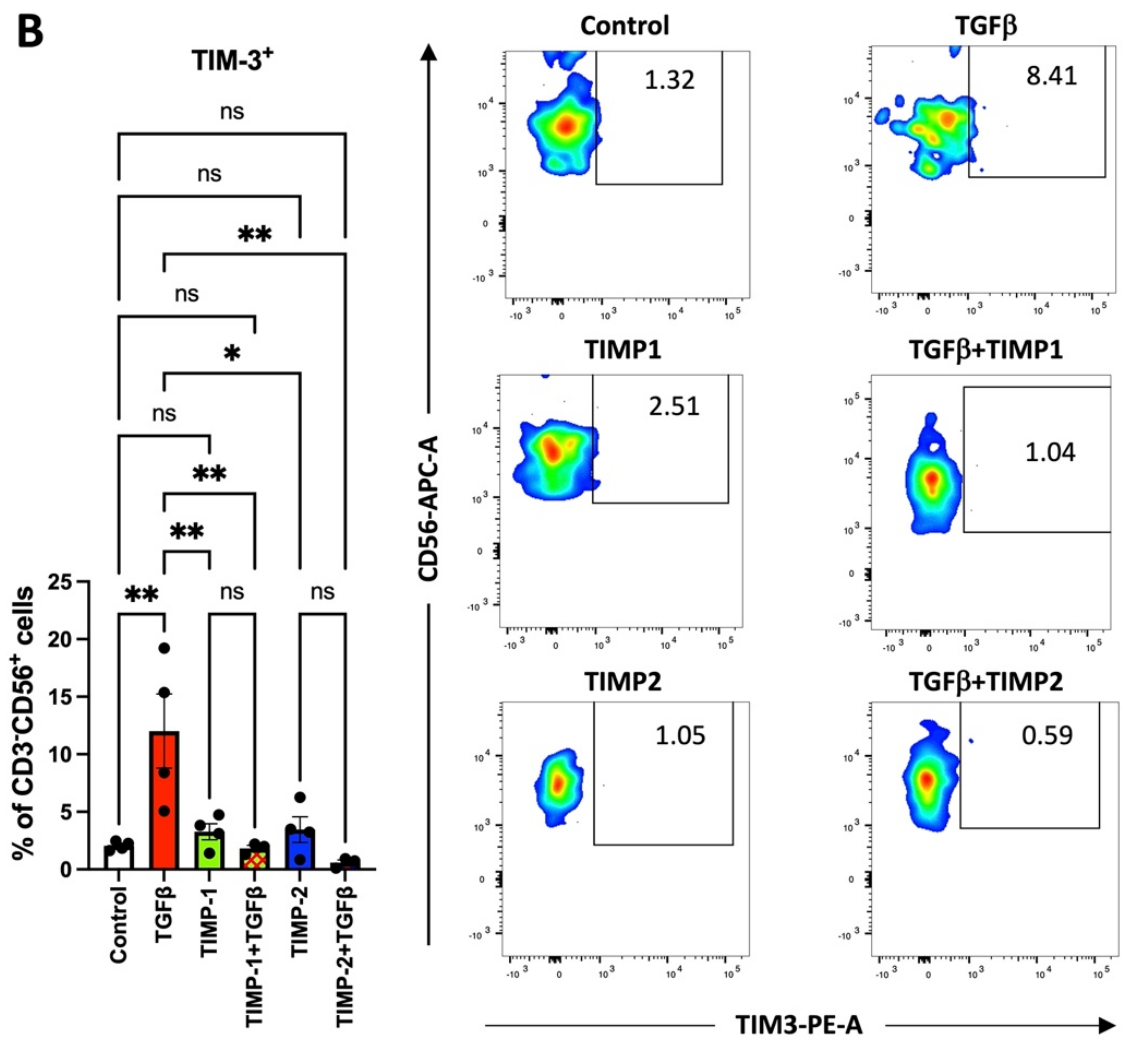

Figure 3. TIMP-1 and TIMP-2 treatments were effective in contrasting the TGF $\beta$-induced ability to decrease the surface expression of the NK cell activation marker NKG2D (panel A) and the expression of the TIM-3 (panel B) exhaustion marker. Results are shown as mean \pm SEM, ANOVA, ns = not signficant; $^{*} p<0.05 ;{ }^{* *} p<0.01 ;{ }^{* * *} p<0.001$. Representative plots are shown. Controls were cells in RPMI medium alone. 


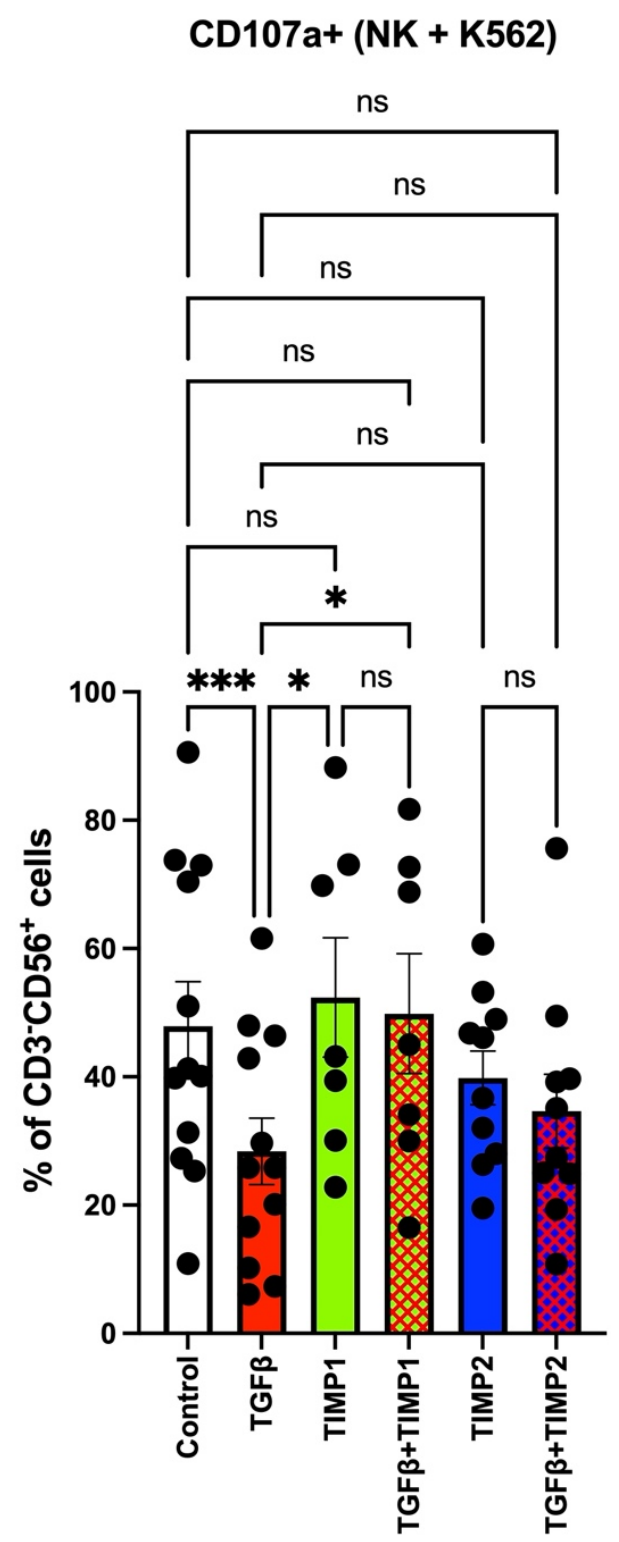

Figure 4. Effects of TIMPs on degranulation capabilities in TGF $\beta$-induced decidual-like NK cells. TIMP-1 was significantly different from TGF $\beta$, and TIMP-1 when combined TGF $\beta$ was able to counteract TGF $\beta$. TIMP-2 did not have a significant ability to revert the impaired degranulation capabilities when combined with TGF $\beta$. The graph shows the specific degranulation in the co-culture system with subtracted basal CD107a levels (in NK cells alone/in absence of cell target). Results are shown as mean \pm SEM, ANOVA, ns $=$ not signficant; ${ }^{*} p<0.05 ;{ }^{* * *} p<0.005$. PBMCs from 7-12 different healthy donors were used. Controls were cells in RPMI medium alone.

\section{Discussion}

ILCs (innate lymphoid cells) represent a recently identified heterogeneous family of mononuclear hematopoietic cells found mostly in solid tissues [21,22]. Based on their lymphoid morphology, surface antigens, transcription factor expression and cytokine production (Th1, Th2 and Th17-like), ILCs have been classified into three major groups, termed ILC1, ILC2 and ILC3 [22]. Whether ILCs can be defined as friends or foes in cancer insurgence and progression is still a matter of debate [21,22,24]. NK cells are innate lymphoid cells involved in tumor immunosurveillance by inducing cancer cell lysis either directly (via perforin/granzyme system) or indirectly (via secretion of TNF $\alpha$ and IFN $\gamma$ ) $[21,25]$. NK cells develop altered immune-suppressive phenotypes in many cancer types. 
Very recently, we found that in peripheral blood from prostate cancer (PCa) patients, NK cells show enhanced CD9, CD49a and CXCR4 expression [33]. PCa TANKs produce factors that are able to support inflammatory angiogenesis in an in vitro model and increase the expression of CXCL8, ICAM-1 and VCAM-1 mRNA in ECs. Secretome analysis revealed the ability of PCa TANKs to release pro-inflammatory cytokines/chemokines involved in monocyte recruitment and M2-like polarization [33].

Apart from anergy, we found that tumor-associated NK cells (TANKs) also in nonsmall cell lung cancer (NSCLC), pleural effusions and colorectal cancers (CRC) acquire pro-angiogenic phenotype and functions [29-33]. We observed that tumor-associated (TANKs) and tumour-infiltrating (TINKs) NK cells in cancer patients can acquire phenotype and functions similar to NK cells in the developing decidua [34-37]. The dNK cells are characterized by a CD56 $6^{\text {superbright }} C D 16^{\text {neg }}$ phenotype and by the presence of CD9 (a member of the tetraspanin protein family that plays a role in cell adhesion and cell motility) and CD49a (an integrin alpha 1 subunit that binds collagen and laminin) [35,38]. These dNK cells are poorly cytotoxic and are necessary to remodel spiral arteries during pregnancy $[34,35,39,40]$. Within the decidua, NK cells have a critical role in the tolerance of the developing fetus, the modulation of angiogenesis and decidualization, all necessary processes associated with pregnancy. dNKs produce angiogenic factors: VEGF, PlGF and IL-8 (CXCL8) [35,39-41], angiogenin [40,41] and angiopoietin 1 and 2 [35,41]. They also support tissue remodeling through the expression of matrix metalloproteinases (MMP-9). MMPs and TIMPs expression were observed in both decidual tissues and in dNK cells [42]. It was found that a wide variety of MMPs are expressed at the human fetal-maternal interface, supporting the highly invasive cellular activity and ECM remodeling that occurs during placental development.

Considering the intriguing dual role of TIMP1 in regulating pathways of cancer progression in a bi-phasic manner as described previously [2,5-7] and recent evidence that TIMPs can function as alarmins [10-12], we examined the effects on ILCs as a focus for our current study. Recently, TIMP1 has also been identified as a new immuneregulator/immune-checkpoint modulator $[9,11,30]$. In the present study, we evaluate the impact of TIMP1 and TIMP2 during NK cell polarization to a pro-angiogenic phenotype by TGF $\beta$. Subsequently, our goal was to determine how extracellular TIMPs can influence tumor-cell-polarized NK cell phenotype and behavior.

Interestingly, some NKG2D ligands (MICA, MICB, ULBP-2 and ULBP-3) are secreted from NSCLC [33], osteosarcomas [44] and gastric [45] cancer cells and may be shed by MMP-mediated cleavage. For example, upregulation of MMP activity can induce a downregulation of expression of NKG2D ligands in gastric cancer cells, leading to lower-level cancer susceptibility of NK cells [45]. Therefore, TIMPs could be relevant in NK cellrecognition activities.

Our current observations suggest that TIMPs can provide important new markers for the diagnosis, classification, prognosis and guide to treatment of the inflammation cells, and common and often aggressive forms of human cancer, such as CRC and PCa.

NK cells from colorectal cancer patients are polarized toward a pro-angiogenic phenotype, and they express angiogenin, MMP2 and MMP9 [30]. We also report that they paradoxically produce higher levels of TIMP-1 and TIMP-2 [30]. TGF $\beta$ mimics the cancer microenvironment. We found that NK cells from healthy donors, when exposed to TGF $\beta$, acquire the $\mathrm{CD} 56^{\text {bright }} \mathrm{CD}^{+} \mathrm{CD} 49 \mathrm{a}^{+}$decidual-like phenotype, together with decreased levels of the activation marker NKG2D. Administration of TIMP1 or TIMP2 proteins was effective in interfering with TGF $\beta$-induced NK cell polarization towards the $\mathrm{CD} 6^{\text {bright }} \mathrm{CD}^{+} \mathrm{CD} 49 \mathrm{a}^{+}$decidual-like phenotype and in the restoration of the levels of the NKG2D activation marker. We found that TIMP-1 was able to restore degranulation capabilities when combined with TGF $\beta$, while TIMP-2 was not significantly efficient in limiting the TGF $\beta$ effect.

In preliminary experiments, we explored the polarizing activities of IL-6, another cytokine present in cancer patients, as compared to TGF $\beta$. The IL-6/JAK/STAT3 signaling 
pathway is aberrantly hyperactivated in patients with hematopoietic malignancies or solid tumors in cancer patients [54,55]. In cytolytic NK cells, we observed that IL-6 was not effective in generating $\mathrm{CD} 566^{\text {bight }} \mathrm{CD} 9^{+} \mathrm{CD} 49 \mathrm{a}^{+} \mathrm{NK}$ cells and did not contribute to the generation of anergic/exhausted NK cells, as TGF $\beta$ does.

TGF $\beta$ has been shown by us and several authors to be a very important protumorigenic, pro-inflammatory and pro-angiogenic factor. We and others have shown how TGF $\beta$ is crucial in NK cells' pro-angiogenic decidual-like polarization.

Our results suggest a potential role of TIMPs in controlling the pro-angiogenic switch induced by TGF $\beta$ in NK cells and suggest a possible use of TIMPs peptides in the reeducation of anergic/pro-angiogenic NK cells.

\section{Conclusions}

Our results provided the rationale that TIMPs can be envisaged as a regulator of NK cells by interfering with TGF $\beta$-induced NK cell polarization and by contrasting the generation of pro-tumor/decidual-like NK cells within the tumor microenvironment. Additionally, the degranulation marker CD 107 decreased by TGF-beta is restored by TIMP1. Therefore, we propose the use of exogenous TIMPs as a potential strategy in the re-education of pro-angiogenic, TGF $\beta$ polarized NK cells, in synergy with agents able to increase degranulation capabilities.

Supplementary Materials: The following are available online at https://www.mdpi.com/article/ 10.3390/cancers13194955/s1, Figure S1: Comparison of the effects of TGF $\beta$ and IL-6 in generating of decidual-like/anergic/exhausted NK cells. Figure S2: Representative gating strategy for NK cell identification and selected decidual-like (CD56bright, CD9, CD49a), activation (NKG2D) and exhaustion (PD-1, TIM-3) detection. Figure S3: The CM of CC and CRC cell lines increase the surface

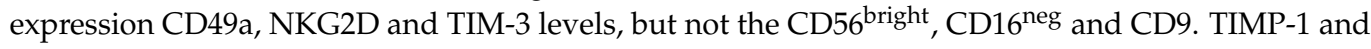
TIMP-2 treatments showed a trend in being effective in regulating divergent CD49a, NKG2D and TIM-3 exhaustion marker. Figure S4: TIMP- 1 and TIMP-2 treatments showed a trend in contrasting the TGF $\beta$-induced ability to increase PD-1 expression in cytolytic NK cells. PBMCs of 6 healthy donors were used. Results are shown as mean \pm SEM, ANOVA. Figure S5: Internal controls for NK cell degranulation capability.

Author Contributions: Conceptualization, A.A., A.B., W.G.S.-S. and D.M.N.; methodology, A.A., M.G., M.T.P., V.C., W.G.S.-S. and A.B.; formal analysis, M.G., M.T.P., A.B. and D.M.N.; data curation, A.A., A.B., R.R. and D.M.N.; writing—original draft preparation, A.B., D.M.N. and A.A.; writing-review and editing, A.A., R.R., A.B., W.G.S.-S. and D.M.N.; funding acquisition, A.A., A.B. and D.M.N. All authors have read and agreed to the published version of the manuscript.

Funding: This research was funded by the Italian Ministry of Health Ricerca Corrente-IRCCS MultiMedica, to A.A., D.M.N. and A.B. and the Italian Ministry of University and Research PRIN 2017 grant 2017NTK4HY, to D.M.N. A.B. has received funds from the Italian Association for Cancer Research (AIRC-MFAG, ID-22818 and the Cariplo Foundation (ID-2019-1609). MG is a participant in the PhD course in Life Sciences and Biotechnology at the University of Insubria and is funded by an “assegno di ricerca" within PRIN 2017 grant 2017NTK4HY.

Institutional Review Board Statement: The study was approved by the institutional review board ethics committees (protocol no. 0024138 04/07/2011 and protocol no.10 2 10/2011) and according to the Helsinki Declaration of 1975 as revised in 2013.

Informed Consent Statement: All healthy donors enrolled in the study signed the informed consent, in accordance with the Helsinki Declaration of 1975 as revised in 2013.

Data Availability Statement: The data presented in this study are available on request from the corresponding author.

Acknowledgments: We thank Martina Cucchiara (IRCCS MultiMedica, Milan, Italy) for preliminary experiments. We also thank Paola Corradino, (IRCCS MultiMedica, Milan, Italy) for support to literature research.

Conflicts of Interest: The authors declare no conflict of interest. 


\section{References}

1. Stetler-Stevenson, W.; Krutzsch, H.; Liotta, L. Tissue inhibitor of metalloproteinase-2 (TIMP-2): A new member of the metalloproteinase inhibitor family. J. Biol. Chem. 1989, 264, 17374-17378. [CrossRef]

2. Jackson, H.W.; Defamie, V.; Waterhouse, P.; Khokha, R. TIMPs: Versatile extracellular regulators in cancer. Nat. Rev. Cancer 2017, 17, 38-53. [CrossRef]

3. Albini, A.; Melchiori, A.; Santi, L.; Liotta, L.; Brown, P.; Stetler-Stevenson, W.G. Tumor cell invasion inhibited by TIMP-2. J. Natl. Cancer Inst. 1991, 83, 775-779. [CrossRef]

4. Remillard, T.C.; Bratslavsky, G.; Jensen-Taubman, S.; Stetler-Stevenson, W.G.; Bourboulia, D. Molecular mechanisms of tissue inhibitor of metalloproteinase 2 in the tumor microenvironment. Mol. Cell Ther. 2014, 2, 17. [CrossRef]

5. Dechaphunkul, A.; Phukaoloun, M.; Kanjanapradit, K.; Graham, K.; Ghosh, S.; Santos, C.; Mackey, J.R. Prognostic significance of tissue inhibitor of metalloproteinase-1 in breast cancer. Int. J. Breast Cancer 2012, 2012, 290854. [CrossRef]

6. Aaberg-Jessen, C.; Christensen, K.; Offenberg, H.; Bartels, A.; Dreehsen, T.; Hansen, S.; Schroder, H.D.; Brunner, N.; Kristensen, B.W. Low expression of tissue inhibitor of metalloproteinases-1 (TIMP-1) in glioblastoma predicts longer patient survival. J. Neurooncol. 2009, 95, 117-128. [CrossRef] [PubMed]

7. Kuvaja, P.; Talvensaari-Mattila, A.; Paakko, P.; Turpeenniemi-Hujanen, T. The absence of immunoreactivity for tissue inhibitor of metalloproteinase-1 (TIMP-1), but not for TIMP-2, protein is associated with a favorable prognosis in aggressive breast carcinoma. Oncology 2005, 68, 196-203. [CrossRef] [PubMed]

8. Bourboulia, D.; Jensen-Taubman, S.; Stetler-Stevenson, W.G. TIMP-2: An Endogenous Angiogenesis Inhibitor with Distinct Antitumoral Properties. Treat. Strateg. Hematol. 2012, 2, 31-35.

9. Guedez, L.; Jensen-Taubman, S.; Bourboulia, D.; Kwityn, C.J.; Wei, B.; Caterina, J.; Stetler-Stevenson, W.G. TIMP-2 targets tumor-associated myeloid suppressor cells with effects in cancer immune dysfunction and angiogenesis. J. Immunother. 2012, 35, 502-512. [CrossRef] [PubMed]

10. Artym, V.V.; Zhang, Y.; Seillier-Moiseiwitsch, F.; Yamada, K.M.; Mueller, S.C. Dynamic interactions of cortactin and membrane type 1 matrix metalloproteinase at invadopodia: Defining the stages of invadopodia formation and function. Cancer Res. 2006, 66, 3034-3043. [CrossRef] [PubMed]

11. Benzing, C.; Lam, H.; Tsang, C.M.; Rimmer, A.; Arroyo-Berdugo, Y.; Calle, Y.; Wells, C.M. TIMP-2 secreted by monocyte-like cells is a potent suppressor of invadopodia formation in pancreatic cancer cells. BMC Cancer 2019, 19, 1214. [CrossRef]

12. Yang, D.; Han, Z.; Oppenheim, J.J. Alarmins and immunity. Immunol. Rev. 2017, 280, 41-56. [CrossRef] [PubMed]

13. Warner, R.B.; Najy, A.J.; Jung, Y.S.; Fridman, R.; Kim, S.; Kim, H.C. Establishment of Structure-Function Relationship of Tissue Inhibitor of Metalloproteinase-1 for Its Interaction with CD63: Implication for Cancer Therapy. Sci. Rep. 2020, 10, 2099. [CrossRef] [PubMed]

14. Angioni, R.; Sanchez-Rodriguez, R.; Viola, A.; Molon, B. TGF-beta in Cancer: Metabolic Driver of the Tolerogenic Crosstalk in the Tumor Microenvironment. Cancers 2021, 13, 401. [CrossRef] [PubMed]

15. Kim, B.G.; Malek, E.; Choi, S.H.; Ignatz-Hoover, J.J.; Driscoll, J.J. Novel therapies emerging in oncology to target the TGF-beta pathway. J. Hematol. Oncol. 2021, 14, 55. [CrossRef] [PubMed]

16. van den Bulk, J.; de Miranda, N.; Ten Dijke, P. Therapeutic targeting of TGF-beta in cancer: Hacking a master switch of immune suppression. Clin. Sci. 2021, 135, 35-52. [CrossRef] [PubMed]

17. Park, S.A.; Kim, M.J.; Park, S.Y.; Kim, J.S.; Lim, W.; Nam, J.S.; Yhong Sheen, Y. TIMP-1 mediates TGF-beta-dependent crosstalk between hepatic stellate and cancer cells via FAK signaling. Sci. Rep. 2015, 5, 16492. [CrossRef]

18. Seo, D.W.; Li, H.; Guedez, L.; Wingfield, P.T.; Diaz, T.; Salloum, R.; Wei, B.Y.; Stetler-Stevenson, W.G. TIMP-2 mediated inhibition of angiogenesis: An MMP-independent mechanism. Cell 2003, 114, 171-180. [CrossRef]

19. Bourboulia, D.; Jensen-Taubman, S.; Rittler, M.R.; Han, H.Y.; Chatterjee, T.; Wei, B.; Stetler-Stevenson, W.G. Endogenous angiogenesis inhibitor blocks tumor growth via direct and indirect effects on tumor microenvironment. Am. J. Pathol. 2011, 179, 2589-2600. [CrossRef]

20. Peeney, D.; Jensen, S.M.; Castro, N.P.; Kumar, S.; Noonan, S.; Handler, C.; Kuznetsov, A.; Shih, J.; Tran, A.D.; Salomon, D.S.; et al. TIMP-2 suppresses tumor growth and metastasis in murine model of triple-negative breast cancer. Carcinogenesis 2020, 41, 313-325. [CrossRef]

21. Tumino, N.; Vacca, P.; Quatrini, L.; Munari, E.; Moretta, F.; Pelosi, A.; Mariotti, F.R.; Moretta, L. Helper Innate Lymphoid Cells in Human Tumors: A Double-Edged Sword? Front. Immunol. 2019, 10, 3140. [CrossRef] [PubMed]

22. Chiossone, L.; Dumas, P.Y.; Vienne, M.; Vivier, E. Natural killer cells and other innate lymphoid cells in cancer. Nat. Rev. Immunol. 2018, 18, 671-688. [CrossRef]

23. Salome, B.; Gomez-Cadena, A.; Loyon, R.; Suffiotti, M.; Salvestrini, V.; Wyss, T.; Vanoni, G.; Ruan, D.F.; Rossi, M.; Tozzo, A.; et al. CD56 as a marker of an ILC1-like population with NK cell properties that is functionally impaired in AML. Blood Adv. 2019, 3, 3674-3687. [CrossRef] [PubMed]

24. Vacca, P.; Munari, E.; Tumino, N.; Moretta, F.; Pietra, G.; Vitale, M.; Del Zotto, G.; Mariotti, F.R.; Mingari, M.C.; Moretta, L. Human natural killer cells and other innate lymphoid cells in cancer: Friends or foes? Immunol. Lett. 2018, 201, 14-19. [CrossRef] [PubMed]

25. Spits, H.; Artis, D.; Colonna, M.; Diefenbach, A.; Di Santo, J.P.; Eberl, G.; Koyasu, S.; Locksley, R.M.; McKenzie, A.N.; Mebius, R.E.; et al. Innate lymphoid cells-A proposal for uniform nomenclature. Nat. Rev. Immunol. 2013, 13, 145-149. [CrossRef] 
26. Pesce, S.; Greppi, M.; Grossi, F.; Del Zotto, G.; Moretta, L.; Sivori, S.; Genova, C.; Marcenaro, E. PD/1-PD-Ls Checkpoint: Insight on the Potential Role of NK Cells. Front. Immunol. 2019, 10, 1242. [CrossRef]

27. Pesce, S.; Greppi, M.; Tabellini, G.; Rampinelli, F.; Parolini, S.; Olive, D.; Moretta, L.; Moretta, A.; Marcenaro, E. Identification of a subset of human natural killer cells expressing high levels of programmed death 1: A phenotypic and functional characterization. J. Allergy Clin. Immunol. 2017, 139, 335-346.e333. [CrossRef]

28. Wu, S.Y.; Fu, T.; Jiang, Y.Z.; Shao, Z.M. Natural killer cells in cancer biology and therapy. Mol. Cancer 2020, 19, 120. [CrossRef]

29. Bosi, A.; Zanellato, S.; Bassani, B.; Albini, A.; Musco, A.; Cattoni, M.; Desio, M.; Nardecchia, E.; D’Urso, D.G.; Imperatori, A.; et al. Natural Killer Cells from Malignant Pleural Effusion Are Endowed with a Decidual-Like Proangiogenic Polarization. J. Immunol. Res. 2018, 2018, 2438598. [CrossRef] [PubMed]

30. Bruno, A.; Bassani, B.; D’Urso, D.G.; Pitaku, I.; Cassinotti, E.; Pelosi, G.; Boni, L.; Dominioni, L.; Noonan, D.M.; Mortara, L.; et al. Angiogenin and the MMP9-TIMP2 axis are up-regulated in proangiogenic, decidual NK-like cells from patients with colorectal cancer. FASEB J. 2018, 32, 5365-5377. [CrossRef]

31. Bruno, A.; Ferlazzo, G.; Albini, A.; Noonan, D.M. A Think Tank of TINK/TANKs: Tumor-Infiltrating/Tumor-Associated Natural Killer Cells in Tumor Progression and Angiogenesis. J. Natl. Cancer Inst. 2014, 106, dju200. [CrossRef] [PubMed]

32. Bruno, A.; Focaccetti, C.; Pagani, A.; Imperatori, A.S.; Spagnoletti, M.; Rotolo, N.; Cantelmo, A.R.; Franzi, F.; Capella, C.; Ferlazzo, G.; et al. The proangiogenic phenotype of natural killer cells in patients with non-small cell lung cancer. Neoplasia 2013, 15, 133-142. [CrossRef]

33. Gallazzi, M.; Baci, D.; Mortara, L.; Bosi, A.; Buono, G.; Naselli, A.; Guarneri, A.; Deho, F.; Capogrosso, P.; Albini, A.; et al. Prostate Cancer Peripheral Blood NK Cells Show Enhanced CD9, CD49a, CXCR4, CXCL8, MMP-9 Production and Secrete Monocyte-Recruiting and Polarizing Factors. Front. Immunol. 2021, 11, 586126. [CrossRef] [PubMed]

34. Blois, S.M.; Klapp, B.F.; Barrientos, G. Decidualization and angiogenesis in early pregnancy: Unravelling the functions of DC and NK cells. J. Reprod. Immunol. 2011, 88, 86-92. [CrossRef]

35. Santoni, A.; Zingoni, A.; Cerboni, C.; Gismondi, A. Natural killer (NK) cells from killers to regulators: Distinct features between peripheral blood and decidual NK cells. Am. J. Reprod. Immunol. 2007, 58, 280-288. [CrossRef]

36. Bassani, B.; Baci, D.; Gallazzi, M.; Poggi, A.; Bruno, A.; Mortara, L. Natural Killer Cells as Key Players of Tumor Progression and Angiogenesis: Old and Novel Tools to Divert Their Pro-Tumor Activities into Potent Anti-Tumor Effects. Cancers 2019, 11, 461. [CrossRef]

37. Albini, A.; Noonan, D.M. Decidual-Like NK Cell Polarization: From Cancer Killing to Cancer Nurturing. Cancer Discov. 2020, 11, 28-33. [CrossRef]

38. Montaldo, E.; Vacca, P.; Chiossone, L.; Croxatto, D.; Loiacono, F.; Martini, S.; Ferrero, S.; Walzer, T.; Moretta, L.; Mingari, M.C. Unique Eomes(+) NK Cell Subsets Are Present in Uterus and Decidua During Early Pregnancy. Front. Immunol. $2015,6,646$. [CrossRef] [PubMed]

39. Hanna, J.; Goldman-Wohl, D.; Hamani, Y.; Avraham, I.; Greenfield, C.; Natanson-Yaron, S.; Prus, D.; Cohen-Daniel, L.; Arnon, T.I.; Manaster, I.; et al. Decidual NK cells regulate key developmental processes at the human fetal-maternal interface. Nat. Med. 2006, 12, 1065-1074. [CrossRef]

40. Wallace, A.E.; Fraser, R.; Gurung, S.; Goulwara, S.S.; Whitley, G.S.; Johnstone, A.P.; Cartwright, J.E. Increased angiogenic factor secretion by decidual natural killer cells from pregnancies with high uterine artery resistance alters trophoblast function. Hum. Reprod. 2014, 29, 652-660. [CrossRef]

41. Lash, G.E.; Schiessl, B.; Kirkley, M.; Innes, B.A.; Cooper, A.; Searle, R.F.; Robson, S.C.; Bulmer, J.N. Expression of angiogenic growth factors by uterine natural killer cells during early pregnancy. J. Leukoc. Biol. 2006, 80, 572-580. [CrossRef]

42. Anacker, J.; Segerer, S.E.; Hagemann, C.; Feix, S.; Kapp, M.; Bausch, R.; Kammerer, U. Human decidua and invasive trophoblasts are rich sources of nearly all human matrix metalloproteinases. Mol. Hum. Reprod. 2011, 17, 637-652. [CrossRef]

43. Le Maux Chansac, B.; Misse, D.; Richon, C.; Vergnon, I.; Kubin, M.; Soria, J.C.; Moretta, A.; Chouaib, S.; Mami-Chouaib, F. Potentiation of NK cell-mediated cytotoxicity in human lung adenocarcinoma: Role of NKG2D-dependent pathway. Int. Immunol. 2008, 20, 801-810. [CrossRef] [PubMed]

44. Sun, D.; Wang, X.; Zhang, H.; Deng, L.; Zhang, Y. MMP9 mediates MICA shedding in human osteosarcomas. Cell Biol. Int. 2011, 35, 569-574. [CrossRef]

45. Shiraishi, K.; Mimura, K.; Kua, L.F.; Koh, V.; Siang, L.K.; Nakajima, S.; Fujii, H.; Shabbir, A.; Yong, W.P.; So, J.; et al. Inhibition of MMP activity can restore NKG2D ligand expression in gastric cancer, leading to improved NK cell susceptibility. J. Gastroenterol. 2016, 51, 1101-1111. [CrossRef]

46. Allan, D.S.; Rybalov, B.; Awong, G.; Zuniga-Pflucker, J.C.; Kopcow, H.D.; Carlyle, J.R.; Strominger, J.L. TGF-beta affects development and differentiation of human natural killer cell subsets. Eur. J. Immunol. 2010, 40, 2289-2295. [CrossRef]

47. Keskin, D.B.; Allan, D.S.; Rybalov, B.; Andzelm, M.M.; Stern, J.N.; Kopcow, H.D.; Koopman, L.A.; Strominger, J.L. TGFbeta promotes conversion of CD16+ peripheral blood NK cells into CD16-NK cells with similarities to decidual NK cells. Proc. Natl. Acad. Sci. USA 2007, 104, 3378-3383. [CrossRef] [PubMed]

48. Cerdeira, A.S.; Rajakumar, A.; Royle, C.M.; Lo, A.; Husain, Z.; Thadhani, R.I.; Sukhatme, V.P.; Karumanchi, S.A.; Kopcow, H.D. Conversion of peripheral blood NK cells to a decidual NK-like phenotype by a cocktail of defined factors. J. Immunol. 2013, 190, 3939-3948. [CrossRef] [PubMed] 
49. Gao, Y.; Souza-Fonseca-Guimaraes, F.; Bald, T.; Ng, S.S.; Young, A.; Ngiow, S.F.; Rautela, J.; Straube, J.; Waddell, N.; Blake, S.J.; et al. Tumor immunoevasion by the conversion of effector NK cells into type 1 innate lymphoid cells. Nat. Immunol. 2017, 18, 1004. [CrossRef]

50. Chowdhury, A.; Brinson, R.; Wei, B.; Stetler-Stevenson, W.G. Tissue Inhibitor of Metalloprotease-2 (TIMP-2): Bioprocess Development, Physicochemical, Biochemical, and Biological Characterization of Highly Expressed Recombinant Protein. Biochemistry 2017, 56, 6423-6433. [CrossRef] [PubMed]

51. Sordo-Bahamonde, C.; Lorenzo-Herrero, S.; Gonzalez-Rodriguez, A.P.; Payer, Á.; Gonzalez-Garcia, E.; Lopez-Soto, A.; Gonzalez, S. BTLA/HVEM Axis Induces NK Cell Immunosuppression and Poor Outcome in Chronic Lymphocytic Leukemia. Cancers 2021, 13, 1766. [CrossRef] [PubMed]

52. Lorenzo-Herrero, S.; Lopez-Soto, A.; Sordo-Bahamonde, C.; Gonzalez-Rodriguez, A.P.; Vitale, M.; Gonzalez, S. NK Cell-Based Immunotherapy in Cancer Metastasis. Cancers 2018, 11, 29. [CrossRef] [PubMed]

53. Lorenzo-Herrero, S.; Sordo-Bahamonde, C.; Gonzalez, S.; Lopez-Soto, A. A Flow Cytometric NK Cell-Mediated Cytotoxicity Assay to Evaluate Anticancer Immune Responses In Vitro. Methods Mol. Biol. 2019, 1884, 131-139. [CrossRef] [PubMed]

54. Jones, S.A.; Jenkins, B.J. Recent insights into targeting the IL-6 cytokine family in inflammatory diseases and cancer. Nat. Rev. Immunol. 2018, 18, 773-789. [CrossRef]

55. Johnson, D.E.; O'Keefe, R.A.; Grandis, J.R. Targeting the IL-6/JAK/STAT3 signalling axis in cancer. Nat. Rev. Clin. Oncol. 2018, 15, 234-248. [CrossRef] 